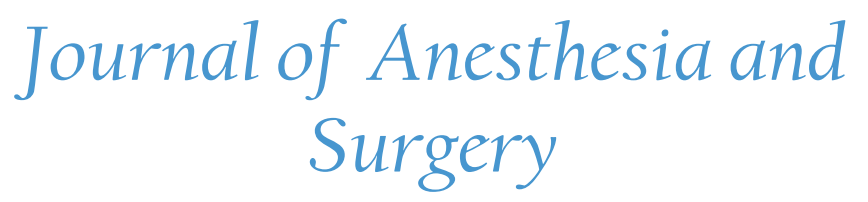

\title{
Usefulness of an Infrared Earphone-Type Thermometer for Pediatric Patients during General Anesthesia: A Pilot Study
}

\author{
Shunsuke Tachibana*, Yumi Igarashi, Michiaki Yamakage \\ Department of Anesthesiology, Sapporo Medical University, School of Medicine, Sapporo, Japan
}

*Corresponding author: Shunsuke Tachibana, M.D, Department of Anesthesiology, Sapporo Medical University School of Medicine, South 1, West16, Chuo-ku, Sapporo, Hokkaido 060-8543, Japan, Tel: +81-11-611-2111 (ext.3570); Fax: +81-11-6319683; E-mail: shunsuke.tachibana@gmail.com

\begin{abstract}
Purpose: We have developed an infrared earphone-type thermometer ("CE-thermo®") able to continuously monitor body temperature in pediatric patients undergoing general anesthesia. In this study, we evaluated the usefulness of this device in pediatric patients receiving general anesthesia for non-cardiac surgery. Methods: After approval from Sapporo Medical University Research Ethics Board, twenty pediatric patients scheduled for non-cardiac surgery under general anaesthesia were enrolled in this study. During general anesthesia, both esophageal temperature (Teso) and tympanic temperature (Ttym, measured by "CE-thermo®") were monitored and continuously recorded for subsequent analysis.

This is a pilot study that enrolled twenty patients scheduled for non-cardiac surgery under general anaesthesia. All patients were ASA physical status 1 or 2 and aged between 4 and 12 years.

Results: The Pearson's correlation coefficient was 0.84 , indicating a strong correlation between oesophageal temperature and tympanic temperature. A Bland-Altman plot showed that the mean bias of the "CE-thermo ${ }^{\circledR}$ " was -0.19 , below that of Teso $\left(2 \mathrm{SD} \pm 0.60^{\circ} \mathrm{C}\right)$.

Conclusion: The new earphone-type thermometer "CE-thermo ${ }^{\circledR}$ " is highly reliable for core body temperature monitoring in pediatric patients during general anesthesia.
\end{abstract}

Received date: November 26, 2017

Accepted date: December 08, 2017

Published date: December 13, 2017

Citation: Tachibana, S., et al. Usefulness of an Infrared Earphone-Type Thermometer for Pediatric Patients during General Anesthesia: a Pilot Study. (2017) J Anesth Surg 4(2): 150153.

\section{DOI: $10.15436 / 2377-1364.17 .101$}

Keywords: Pediatric anesthesia; Disposable earphone-type thermometer; Core body temperature monitoring; Non-cardiac surgery

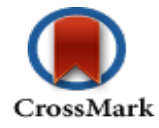

\section{Introduction}

Monitoring and maintaining core body temperature effectively during general anaesthesia is critical in order to avoid preoperative complications caused by hyperthermia and hypothermia. In the case of malignant hyperthermia, abnormal elevation of body temperature must be detected and investigated timely to institute effective intervention ${ }^{[1,2]}$. If not in malignant hyperthermia cases, overwhelmed heat by perioperative warming may raise the core body temperature too much during paediatric anesthesia. However, in perioperative surgery, the incidence of careless hypothermia is much higher than hyperther$\mathrm{mia}^{[3]}$. Perioperative hypothermia can cause adverse events such as life-threaten arrhythmias ${ }^{[4]}$, an increased incidence of surgical site infections $(\mathrm{SSI})^{[5]}$, abnormalities of haemostasis ${ }^{[6,7]}$, and post-operative shivering ${ }^{[8,9]}$. Although, anesthesiologists routinely monitor core body temperature during anesthesia via the oesophageal, tympanic, rectal or bladder routes, temperature monitoring using these sites may be invasive and/or inaccurate ${ }^{[10-12]}$. Selecting a suitable device to monitor core body temperature may be particularly difficult in paediatric anesthesia.

We have previously reported a disposable, earphone-type infrared tympanic thermometer ("CE-thermo®"), able to continuously monitor tympanic membrane temperature, which reflects internal carotid artery temperature and internal jugular vein ${ }^{[13]}$. We have recently developed a disposable infrared earphone-type thermometer that can monitor perioperative core body temperature in paediatric patients. In this observation study, we evaluated the usefulness of the new earphone-type 
thermometer in paediatric patients undergoing general anesthesia for non-cardiac surgery.

\section{Methods}

Ethical approval for this study was provided by the Sapporo Medical University Research Ethics Board, Sapporo, Japan, on 15 November 2014 (2014: No. 262-103; Chairperson: N. Masumori). The trial was registered at the UMIN-Clinical Trials Registry (UMIN000016147) before patient recruitment. Informed consent was obtained from all patients' parents and written assent was obtained from each patient if they can write own their name?

Twenty patients, all American Society of Anesthesiologists Physical Status (ASA-PS) 1 or 2, and aged between 4 and 12 , scheduled for non-cardiac surgery under general anesthesia, were enrolled in this study. Patients with esophageal lesions and/or external auditory canal abnormalities were excluded. No premedication was given. On admission to the operating room (OR), a $22 \mathrm{G}$ intravenous catheter was inserted into the antecubital vein of the left arm, and infusion of bicarbonate Ringer's solution warmed to $37.0^{\circ} \mathrm{C}$ was commenced.

General anesthesia was induced with intravenous thiamylal $(5 \mathrm{mg} / \mathrm{kg})$ and fentanyl $(1.0-2.0 \mu \mathrm{g} / \mathrm{kg})$. Tracheal intubation was performed after administering $0.6 \mathrm{mg} / \mathrm{kg}$ rocuronium. Anesthesia was maintained with $2.0-3.0 \%$ sevoflurane, adjusted to maintain mean arterial pressure within $80-120 \%$ of baseline values in a mixture of $2 \mathrm{~L} / \mathrm{minor}$ and $2 \mathrm{~L} / \mathrm{min}$ oxygen. Fentanyl was administered intermittently as an adjuvant analgesic during surgery. After intubation, the anesthesiologist in attendance used a forced-air warming system (Bair Hugger ${ }^{\mathrm{TM}}$; $3 \mathrm{M}, \mathrm{MN}$ ) to maintain normothermia. The temperature of the Bair Hugger ${ }^{\mathrm{TM}}$ was set to $38.0^{\circ} \mathrm{C}$ during general anesthesia, and discontinued if the patient's oesophageal temperature exceeded $38.0^{\circ} \mathrm{C}$. After induction of general anaesthesia, an esophageal temperature probe (Nova temp®; NOVAMED, NY) was inserted into the oesophagus under direct observation of the perform sinus using the McGrath ${ }^{\circledR}$ MAC (Aircraft Medical Co., Ltd., UK). McGrath ${ }^{\circledR}$ MAC is the device which can help to incubate the tube in nature, but in this study, we used it in order to guide the oesophageal probe into oesophagus safely and properly. The earphone-type thermometer "CE-thermo ${ }^{\circledR}$ " was then attached to the external auditory canal. Oesophageal temperature (Teso) and Tympanic membrane temperature (Ttym), measured by each device respectively, were monitored and continuously recorded to a laptop computer at one minute intervals until just before discontinuation of sevoflurane. During the study period, ambient temperature was maintained between $22-23.0^{\circ} \mathrm{C}$ and humidity kept at $40 \%$.

The Ttym measured by the new earphone-type infrared tympanic thermometer was evaluated in comparison with Teso. Pearson's correlation and Bland-Altman plots were used to compare Teso and Ttym. Bland-Altman plotting was also used to evaluate the limits of agreement between Teso and Ttym. Judging from the past studies, mean differences (bias) $>0.4^{\circ} \mathrm{C}$ and two standard deviations $(\mathrm{SD})>\mathrm{v} \pm 1.0^{\circ} \mathrm{C}$ were also defined as being statistically significant ${ }^{[13,14]}$.

\section{Results}

We enrolled 20 pediatric patients aged between 4 and 12 years in this study. From these, we collected a total of 1,732 values each for Teso and Ttym. Data were extracted from six cases of ontological surgery, five cases of dermatological surgery, four cases of orthopaedic surgery, three cases of ophthalmologic surgery, one case of gynaecological surgery, and one case of neurosurgery. Any monitoring artifacts caused by bipolar high-frequency coagulation were disregarded and not included in the analysis.

The mean age of participants was 6.5 years (IQR: 5.010.3 ), median duration of surgery was $50 \mathrm{~min}$ (IQR: 28-83), and median duration of general anesthesia was 116 min (IQR: 90161).

Figure-1 shows Pearson's correlation coefficient (r), which was 0.84 , indicating a strong correlation between Teso and Ttym. Figure- 2 shows the Bland-Altman plot between Teso and Ttym. The mean bias of the earphone type thermometer was - $0.19^{\circ} \mathrm{C}$ below the Teso with $2 \mathrm{SD} \pm 0.60^{\circ} \mathrm{C}$. There were no complications related to the site of insertion of the oesophageal probe or attachment of the earphone-type thermometer.

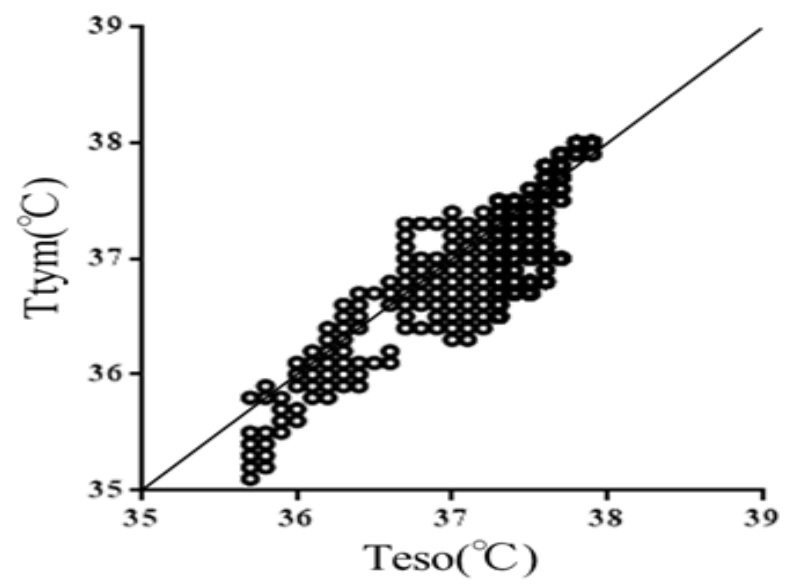

Figure 1: Plotting of tympanic membrane temperature (Ttym) and esophageal temperature (Teso). A strong correlation is shown between Ttym and Teso. (Pearson's correlation coefficient: 0.84).

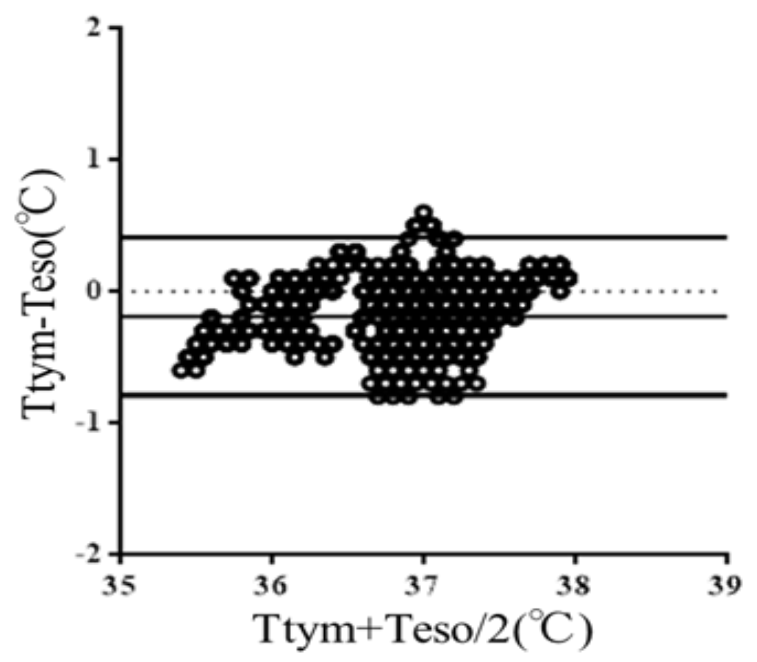

Figure 2: Bland-Altman plot of Teso and Ttym. The mean bias of the earphone type thermometer is $-0.19^{\circ} \mathrm{C}$ below Teso $\left(2 \mathrm{SD} \pm 0.60{ }^{\circ} \mathrm{C}\right)$. 


\section{Discussion}

Monitoring of core body temperature is especially important in pediatric patients because the relative body surface area of a child is larger than that of an adult. These patients also have less subcutaneous fatty tissue compared to adults, while the hypothalamic temperature control centre is not fully developed ${ }^{[15]}$. As such, accurate monitoring of body temperature should be instituted during general anesthesia and patients warmed appropriately.

Body temperature in pediatric anesthesia is generally monitored via probes placed in the oesophagus, rectum or bladder. Data gathered from adult surgery cases have shown that measurement of rectal and bladder temperatures is less reliable in lower abdominal surgery, because it is influenced by ambient temperature ${ }^{[16]}$. Measurement of Teso has high reliability for core body temperature monitoring; however, insertion of an oesophageal probe can only be applied under general anesthesia in non-cardiac surgery. Incorrect temperature monitoring will poorly reflect real values and may fail to detect drastic changes in core body temperature. In addition, the insertion of invasive probes may damage tissues and mucous membranes.

Measurement of Ttym has been established as a suitable method because the blood flow to the tympanic membrane is directly supplied by the internal carotid artery ${ }^{[17]}$, and a disposable, non-invasive earphone-type infrared tympanic thermometer is already available for clinical use under general anesthesia. In adult patients, this device has been proven to be non-invasive, reliable, simple to use and good following performance. Additionally, this tympanic thermometer enables continuous monitoring of core body temperature during anesthesia. The adult model is however not suitable for the pediatric patient's ear canal because of its larger size. To resolve this problem, we have developed a smaller infrared earphone-type thermometer "CE-thermo ${ }^{\circledR}$ " for use in pediatric patients, operating on the same principles as the adult model. The portion of the new "CE-thermo ${ }^{\circledR}$ " in contact with the external auditory canal is made of silicon (hardness: 55), has a soft consistency, and carries a lower risk of skin damage (Figure-3 a-b).

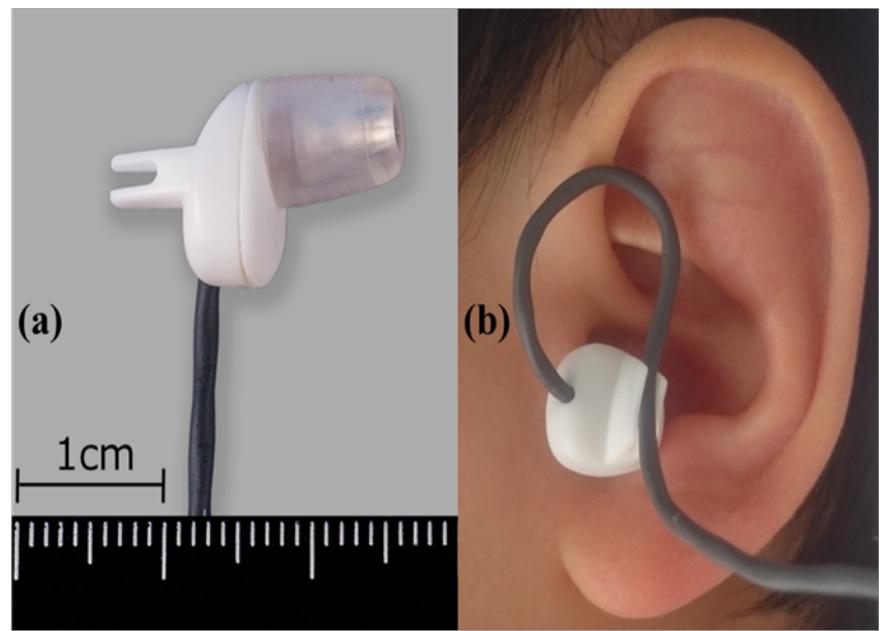

Figure 3: (a) The "CE-thermo ${ }^{\circledR "}$ for pediatric patients is inserted into either the left or right ear canal.

The probe surface in contact with the external auditory canal is made of silicon.

(b) Clinical use of the device: the photograph shows attachment of the "CE-thermo ${ }^{\circledR}$ " in the left ear of a 4-year-old-boy. Use of this new device is recommended in children above the age of 4 years.
Bland-Altman analysis in this study revealed repeatability and low bias. This indicates that the "CE-thermo ${ }^{\circledR}$ " for pediatric patients is highly reliable for measurement of core body temperature during general anesthesia. And this device also used for propofol sedation ${ }^{[18]}$ and procedure under regional anesthe$\mathrm{sia}^{[19]}$. It can be another advantage to attach the earphone-type thermometer painlessly.

There remain some issues regarding this device. Firstly, in some cases, there may be a delay (around two minutes) to obtain temperature values after device attachment. This may be due to misalignment of the sensor with the tympanic membrane. In other cases, proper contact between the silicon surface of the device and the external auditory canal may be suboptimal.

Secondly, this newly developed device is not suitable in certain types of surgery such as craniotomy, ontological surgery and neck surgery. Surgical preparation above the neck can directly interfere with monitoring of tympanic temperature. Covering the whole ear with a sterile occlusive dressing just after insertion of "CE-thermo ${ }^{\circledR}$ " might resolve this problem. Thirdly, inflammation of the middle or external ear may impede accurate monitoring of tympanic temperature. We should check whether obtained values are correct or not, because the qualifying pediatric patients between $4-12$ years tend to be affected with otitis media. In clinical research, Doğan H.H., et al. presented that the infected ears had an around $0.5^{\circ} \mathrm{C}$ higher temperature than non-infected ears ${ }^{[20]}$.

Since this study is a small observation test with 20 subjects, it is necessary to conduct a multicentric study in order to judge the effectiveness and safety of new earphone-type thermometer.

\section{Conclusion}

Pearson's correlation and Bland-Altman analysis of the temperature values obtained from the new tympanic thermometer for pediatric patients suggest that this device is reliable for core body temperature monitoring. This device is furthermore simple to use, non-invasive, and is a hygienic and disposable product.

Conflict of interest: The authors declare no conflict of interest. 


\section{References}

1. Hopkins, P.M. Malignant hyperthermia: advences in clinical management and diagnosis. (2000) Br J Anaesth. 85(1): 118-128.

Pubmed | Crossref | Others

2. Wappler, F., Fiege, M., Schulte am Esch, J. Path physiological role of the serotonin system in malignant hyperthermia. (2001) Br J Anaesth 87(5): 794-798.

Pubmed | Crossref | Others

3. Moola, S., Lockwood, C. Effectiveness of strategies for the management and/or prevention of hypothermia within the adult perioperative environment. (2011) Int J Evid Based Healthc 9(4): 337-345.

Pubmed | Crossref | Others

4. Frank, S.M., Fleisher, L.A., Breslow, M.J., et al. Perioperative maintenance of normothermia reduces the incidence of morbid cardiac events. A randomized clinical trial. (1997) JAMA 277 (14): 1127-1134. Pubmed | Crossref | Others

5. Kurz, A., Sessler, D.I., Lenhardt, R. Perioperative normothermia to reduce the incidence of surgical-wound infection and shorten hospitalization. Study of Wound Infection and Temperature Group. (1996) N Engl J Med 334(19): 1209-1215.

Pubmed | Crossref | Others

6. Rohrer, M.J., Natale, A.M. Effect of hypothermia on the coagulation cascade. (1992) Crit Care Med 20(10): 1402-1405.

Pubmed | Crossref | Others

7. Michelson, A.D., MacGregor, H., Barnard, M.R., et al. Reversible inhibition of human platelet activation by hypothermia in vivo and in vitro. (1994) Thromb Haemost 71(5): 633-640.

Pubmed | Crossref | Others

8. Sessler, D.I., Israel, D., Pozos, R.S., et al. Spontaneous post-anesthetic tremor does not resemble thermoregulatory shivering. (1988) Anesthesiology 68(6): 843-850.

Pubmed | Crossref | Others

9. Frank, S.M., Fleisher, L.A., Olson, K.F., et al. Multivariate determinants of early postoperative oxygen consumption in elderly patients. Effects of shivering, body temperature, and gender. (1995) Anesthesiology. 83(2): 241-249.

Pubmed | Crossref | Others

10. Severinghaus, J.W. Temperature gradients during hypothermia. (1959)Ann NY Acad Sci 80: 515-521.

Pubmed | Crossref | Others
11. Benzinger, M. Tympanic thermometry in surgery and anesthesia. (1969) JAMA 209(8): 1207-1211.

Pubmed | Crossref | Others

12. Frank, S.M., Nguyen, J.M., Garcia, C.M., et al. Temperature monitoring practices during regional anesthesia. (1999) Anesth Analg 88(2): 373-377.

Pubmed | Crossref | Others

13. Tomohiro, K., Yamakage, M., Tomo, H., et al. The usefulness of earphone-type infrared tympanic thermometer for intraoperative core temperature monitoring. (2007) Anesth Analg 105(6): 1688-1692.

Pubmed | Crossref | Others

14. Bock, M., Hohlfeld, U., von Engeln, K., et al. The accuracy of a new infrared ear thermometer in patients undergoing cardiac surgery. (2005) Can J Anaesth 52(10): 1083-1087

Pubmed $\mid$ Crossref $\mid$ Others

15. Bissonnette, B. Temperature monitoring in pediatric anesthesia. (1992) Int Anesthesiol Clin 30(3): 63-76.

Pubmed $\mid$ Crossref $\mid$ Others

16. Harioka, T., Sone, T., Nomura, K., et al. Effects of surgical site and inspired gas warming devices on body temperature during lower abdominal and thoracic surgery. (1992) J Anesth 6(4): 467-473.

Pubmed | Crossref $\mid$ Others

17. Lorr, D., Lund, A., Fredrikson, M., et al. Tympanic menmbrane temperature decreases duing head up tilt: relation to frontal lobe oxygenation and middle cerebral artery mean blood flow velocity. (2017) Scand J Clin Lab Invest 77(8): 587-591.

Pubmed | Crossref | Others

18. Noguchi, I., Matsukawa, T., Ozaki, M., et al. Propofol in low doses causes redistribution of body heat in male volunteers. (2002) Eur J Anaesthesiol 19(9): 677-681.

Pubmed | Crossref | Others

19. Matsukawa, T., Sessler, D.I., Christensen, R. Heat flow and distribution during epidural anesthesia. (1995) Anesthesiology 83(5): 961-967. Pubmed $\mid$ Crossref $\mid$ Others

20. Doğan, H.H., Sezer, R.G., Kırkgöz, T. Comparison of axillary and tympanic temperature measurements in children diagnosed with acute otitis media. (2016) Int J Pediatr 2016: 1729218.

Pubmed | Crossref $\mid$ Others
Ommega Online Publishers

Journal Title: Journal of Anesthesia and Surgery (JAS)

Journal Short Name: J Anesth Surg
Journal ISSN: 2377-1364

E-mail: anestheisa@ommegaonline.com

Website: www.ommegaonline.org 